\title{
THE IMPACT OF DENTAL TREATMENTS ON BLOOD PRESSURE VARIATIONS
}

\section{ABSTRACT}

Objectives: The aim was to determine whether there are alterations in the fluctuations of systolic and diastolic blood pressure or the heart rate of normotensive versus hypertensive participants undergoing antihypertensive treatment during surgical and non-surgical dental treatments, regarding whether or not anaesthetics were used with a vasoconstrictor.

Materials and methods: A prospective, observational, epidemiological study was conducted in a sample of 200 participants older than 65 years (100 normotensive and 100 hypertensive participants on antihypertensive treatment). Five periods for evaluation were established. Demographic information was obtained regarding whether or not anaesthetics were used (with or without a vasoconstrictor) and whether or not the participants underwent surgical treatment. The statistical analysis consisted of a doubly multivariate analysis of repeated measures for multiple dependent variables.

Results: Significant differences were observed in the evolution of systolic blood pressure, with an initial increase in participants undergoing surgical treatment and those without a vasoconstrictor. On the other hand, systolic blood pressure decreased with non-surgical treatments, but it remained stable with the use of a vasoconstrictor. Diastolic blood pressure showed no interaction effect in participants undergoing surgical or non-surgical treatments; with the use of a vasoconstrictor, it initially decreased, while in the absence of a vasoconstrictor, it increased. Heart rate initially decreased in participants undergoing surgical and non-surgical treatments and was analogous whether or not a vasoconstrictor was used.

Conclusions: During blood pressure monitoring, blood pressure variations occur, but there is no clinical repercussion in participants because once the treatment is completed, the initial values are recovered.

Arterial hypertension is a pathology of high prevalence that tends to increase with age. The blood pressure response to surgical and non-surgical dental treatments and the effect of local anaesthetics is important because follow-up and blood pressure control in older patient cohorts can improve dental and clinical management.

Keywords: Blood pressure, hypertension, diastolic pressure, systolic pressure
D*Belisa Olmo-González ${ }^{1}$, (D) Miguel Ángel González-Martín², (D) José Manuel Olmo-Villaseca ${ }^{3}$, (iD)Anna Mañes-Medina ${ }^{1}$, (D)Manuel Ribera-Uribe ${ }^{1}$

ORCID IDs of the authors:

B.O.G.0000-0002-3074-7987

M.A.G.M.0000-0001-5256-878X

J.M.O.V.0000-0003-3460-9036

A.M.M.0000-0002-8970-077X

M.R.U.0000-0002-9919-3281

\footnotetext{
1 Department of Special Patients and Gerodontology, Faculty of Dentistry, International University of Catalonia, Barcelona, Spain

2 Medical Department Amgen Laboratories, Barcelona, Spain.

${ }^{3}$ Medical Specialist in Family and Community Medicine, Sabadell, Spain.
}

$\begin{array}{ll}\text { Received } & : 28.10 .2018 \\ \text { Accepted } & : 23.01 .2019\end{array}$

How to Cite: Gonzalez BO, Martin MAG, Villaseca JMO, Medina AM, Uribe MR. The Impact of Dental Treatments on Blood Pressure Variations. Cumhuriyet Dent J 2019;22:1:74-82.

*Corresponding Author

International University of Catalunya, Josep Trueta s/n, 08195 Sant Cugat del Vallès, Barcelona.

Phone: +34935042000 E-mail: b.olmo@uic.es 


\section{INTRODUCTION}

Arterial hypertension (AH) is a pathology of high prevalence that tends to increase with age. ${ }^{1,2}$ It is a global health problem, and according to the World Health Organization (WHO), $\mathrm{AH}$ is one of the main risk factors for cardiovascular disease.

A dentist can provide a valuable public health service by regularly checking the blood pressure (BP) of their patients. However, a dentist cannot diagnose $\mathrm{AH}$ based on momentary actions, but must inform the patient when the values are suggestive of hypertension, suggest lifestyle behaviours and refer the patient to a specialist for further testing ${ }^{1,3-5}$ to obtain a correct diagnosis.

The response of BP to dental treatment is conditioned by factors that the dentist should try to reduce, such as physical and psychological stress, environment, humoral factors, central stimuli and neural reflexes. ${ }^{6-8}$ Another determining factor is the possibility of finding patients with white coat hypertension $(\mathrm{WCH})$ in the dental clinic. Although WCH is observed with a higher frequency in patients who experience a greater increase in BP under psychological stress, ${ }^{9}$ most patients exhibit a higher BP in the office than outside. ${ }^{10}$ The objective of the present study was to evaluate the impact of surgical and nonsurgical dental treatments, with or without the use of anaesthetics with a vasoconstrictor, on BP variations in a sample of two adult populations of normotensive participants and hypertensive participants undergoing antihypertensive treatment $>65$ years of age.

\section{MATERIALS AND METHODS}

\section{Study design}

This was a prospective, observational study, approved by the Ethics Committee of the International University of Catalonia (Universitat Internacional de Catalunya), Barcelona, Spain (A-09JCT09). The experimental protocol was carried out according to the principles stated in the Declaration of Helsinki. The study was carried out with the collaboration of the Area of Special Patients and Gerodontology of the Faculty of Dentistry of the International University of

\section{Catalonia (Universitat Internacional de Catalunya).}

The notifying document was delivered to the participants, and informed consent was obtained from all the participants.

\section{Study population}

The sample consisted of participants over 65 years of age who attended the University Dental Clinic (Clínica Universitaria Odontológica- CUO) of the International University of Catalonia (Universitat Internacional de Catalunya). The inclusion criteria were (i) participants over 65 years of age, (ii) not classified as American Society of Anaesthesiologists (ASA) group IV or $\mathrm{V}$, and (iii) without pheochromocytoma, hyperthyroidism, uncontrolled asthma, uncontrolled diabetes and/or allergy to sulfites.

The sample consisted of 200 participants (100 normotensive and 100 hypertensive participants treated with antihypertensive drugs). Each sample group consisted of the same number of participants $(n=50)$ with surgical treatment versus non-surgical treatment. In the surgical group, 25 participants had anaesthetics with a vasoconstrictor and 25 had anaesthetics without a vasoconstrictor. The non-surgical group consisted of 25 participants without an anaesthetic versus 25 participants under anaesthesia (20 with a vasoconstrictor and five without). The participants were classified as normotensive or hypertensive with antihypertensive treatment based on the medical history provided by the participant.

\section{Study variables}

The demographic data of age and gender were obtained, in order to verify the homogeneity of the study populations in relation to these variables. The dependent variables were systolic blood pressure (SBP), diastolic blood pressure (DBP) and heart rate (HR). The independent variables were the time in which the BP was measured during a dental visit (before, during or after the dental treatment was completed), whether or not dental anaesthesia was used with/without a vasoconstrictor and surgical or non-surgical treatment. 


\section{Statistical analysis}

A doubly multivariate analysis of repeated measures was applied for multiple dependent variables. The SBP, DBP and HR of the subjects were measured, grouped by normotensive or hypertensive participants with antihypertensive treatment, at different times throughout the dental intervention. The multivariate approach was considered in relation to the time variable to avoid the sphericity assumption, and several dependent variables were included to apply a doubly multivariate design. For each effect, a test was obtained on an optimally weighted combination of the three dependent variables. When the test of the doubly multivariate analysis was significant, posthoc tests of said effect were performed on each dependent variable, providing some protection against inflation of the $\alpha$ with multiple dependent variables.

\section{Technique and data collection instruments}

The clinical history form of the International University of Catalonia (Universitat Internacional de Catalunya- CUO) was included with the study registration form collecting sociodemographic data (age, sex). The type of dental treatment was specified, differentiating surgical and non-surgical treatments, whether or not dental anaesthetics were used with a vasoconstrictor (articaine with adrenaline $1 / 100,000$ ) or without a vasoconstrictor (with mepivacaine), the anaesthetic technique and the number of carpules used. Five timepoints were established to measure BP fluctuations: level 1, at 5 minutes before the intervention; level 2, 1 st measurement at the beginning of the intervention; level 3, 2nd measurement at 5 minutes after the intervention; level 4, 3rd measurement at 10 minutes after the intervention; and level 5, at 15 minutes after the intervention. The participant's BP was recorded using a digital sphygmomanometer (OMROM M6 digital sphygmomanometer model (HEM-7001-I), OMRON HEALTHCARE Co., Ltd, Kyoto, Japan), which is validated for use in elderly patients $^{11}$, and a Holter (BP PM50 NIBP/SPO2Holter model, Contec Medical Systems Co.,Ltd, US), which is an appropriate method for elderly patients. $^{12}$ The participants were instructed to avoid exercising, ingesting caffeine or smoking for 30 minutes prior to the BP measurement and to rest for 5 minutes in a sitting or lying position before proceeding with the BP measurement. Normally, the BP was similar in both arms, but if the difference was equal to or greater than $10 \mathrm{~mm}$ $\mathrm{Hg}$, the measurement was carried out in the arm that produced the highest values.

\section{RESULTS}

The homogeneity of the sociodemographic profile of the different groups of participants was analysed. Both p-values of Pearson's Chi ${ }^{2}$ test for the comparison of proportions were 0.473 , which indicates that there were no significant differences between gender according to BP levels or the type of treatment, surgical or non-surgical. The MannWhitney distribution comparison test indicated that there were no significant differences in the age of the participants according to BP level or treatment ( $\mathrm{p}=0.165$ and $\mathrm{p}=0.935$, respectively).

\section{Evaluation of the effect of time, group and treatment}

In the two study populations, whether or not subjected to surgical treatment, the time factor implied a similar evolution of the study variables without distinguishing between groups of normotensive versus hypertensive participants with antihypertensive treatment. Therefore, a progressive increase in SBP was seen among the different measurement timepoints up to level 4 of the intervention period ( $\mathrm{p}=\mathrm{NS}$ between each of the intervals), followed by a significant fall $(\mathrm{p}=0.015)$, until the recovery of the initial levels in the last measurement. From the initial determination until the beginning of the intervention (timepoints 1 and 2) there was a significant decrease in DBP $(\mathrm{p}=0.001)$ and HR $(\mathrm{p}=0.0001)$, producing a significant rise in DBP $(\mathrm{p}=0.019)$ and HR $(\mathrm{p}=0.0001)$, until the recovery of the initial levels in the last measurement. (Figure 1). 

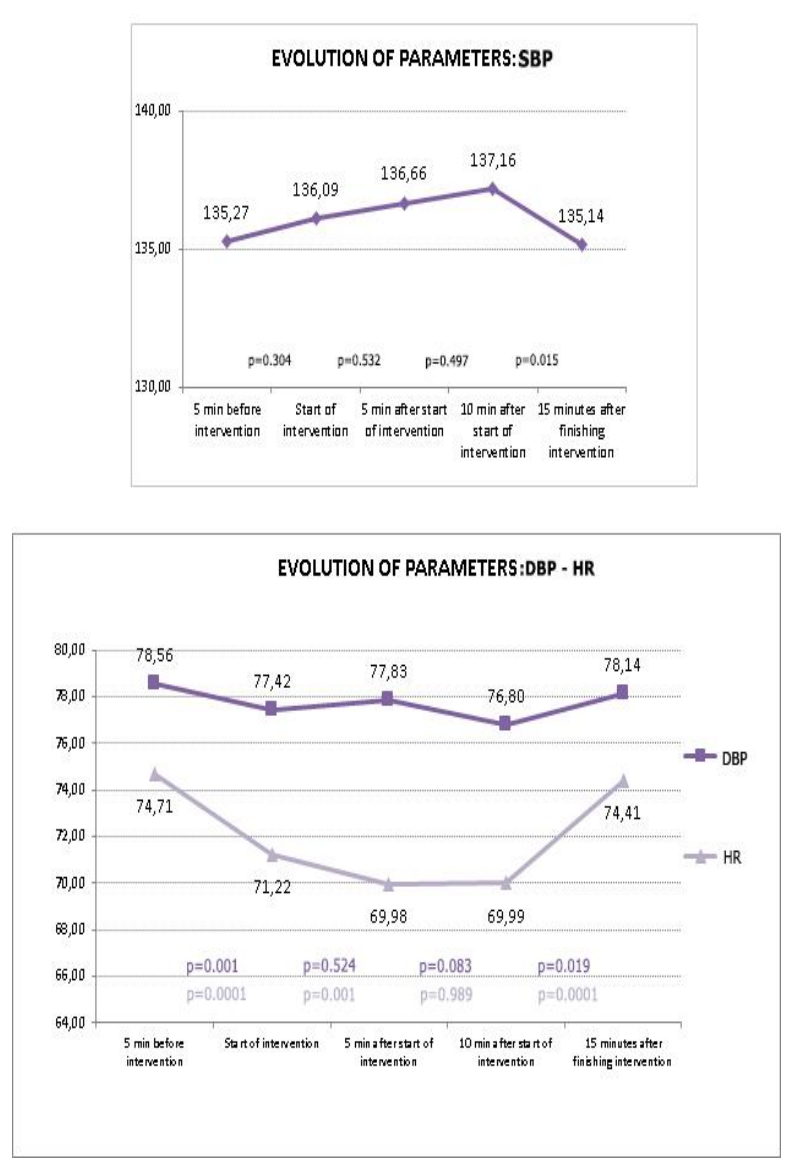

Figure 1. Evolution of SBP, DBP and HR. Evolution over time through five timepoints.

The evolution of some of the study variables was not the same in the participants undergoing surgical versus non-surgical treatments, without distinguishing between groups of normotensive versus hypertensive participants with antihypertensive treatment. Therefore, from the initial determination to the start of the intervention (timepoints 1 and 2 of measurement), there was an increase in SBP with surgical treatments, while there was a decrease with non-surgical treatments; the difference was significant $(p=0.002)$. In the surgical group, SBP remained stable until it decreased at the end of the surgical process (last measurement moment), while in the non-surgical group, a progressive increase occurred, with a significant difference between the two interventions after 15 minutes of the intervention $(\mathrm{p}=0.001)$ (Figure 2).

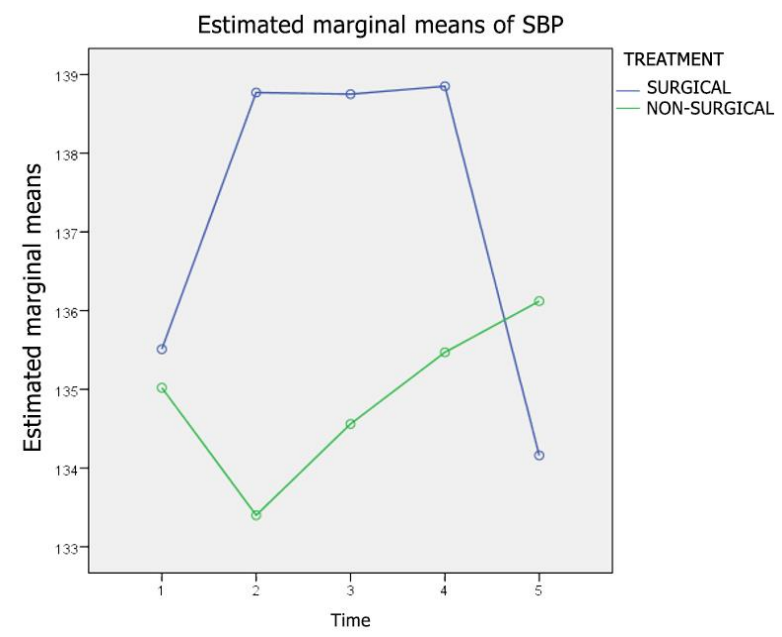

Figure 2. Estimated marginal means of the SBP (interaction effect between time and treatment). Evolution over time through five timepoints of measurement.

Regarding the effect of surgical versus nonsurgical treatments, no significant differences were observed in DBP, but they were observed in relation to HR, resulting in a decrease in the two treatment groups to similar levels. This decrease in HR was more marked and significant in the surgical treatment group $(\mathrm{p}=0.003)$, from the initial determination until the beginning of the intervention (timepoints 1 and 2), and more progressive in the non-surgical treatment group. Once the surgical or non-surgical treatment was finished (timepoint 4), there was an increase in HR to baseline levels, being more accentuated and significant in the surgical treatment group after 15 minutes of the intervention $(\mathrm{p}=0.032)$ (Figure 3$)$.

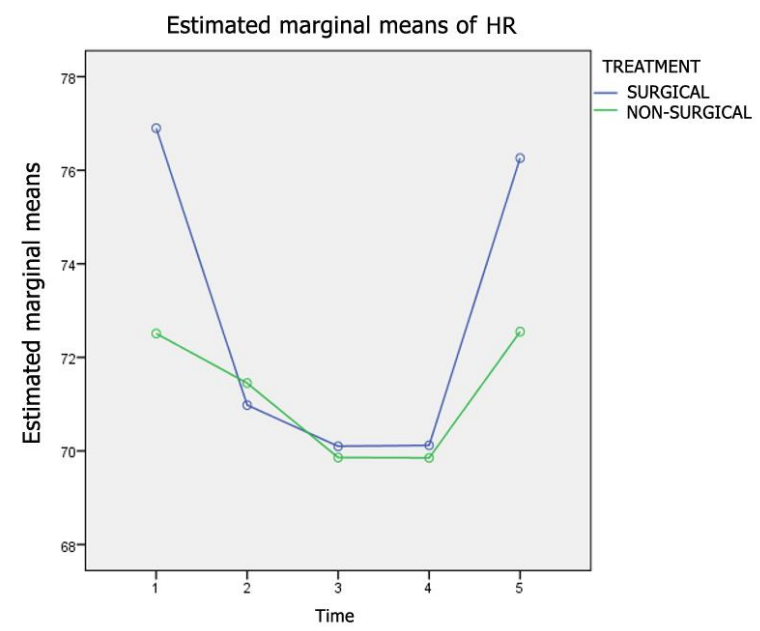

Figure 3. Estimated marginal means of HR (interaction effect between time and treatment). Evolution over time through five timepoints.

In the two study populations, the type of dental treatment, surgical or non-surgical, implied significant differences in the evolution of the 
study variables. In hypertensive participants, a decrease in HR in the two treatment groups was observed, to similar levels, from the initial determination to the start of the intervention (timepoints 1 and 2). In normotensive participants, there was a decrease in HR with surgical treatments and an increase with non-surgical treatments, and there was a significant difference between the two groups depending on the type of treatment $(\mathrm{p}=0.005)$. Between 5 and 10 minutes of the intervention (timepoints 3 and 4), in hypertensive participants, there was a decrease in HR with surgical treatments and an increase with non-surgical treatments; while in normotensive participants, there was an increase with surgical treatments and a decrease with non-surgical treatments, producing a significant difference between them $(\mathrm{p}=0.003)$ (Figure 4).
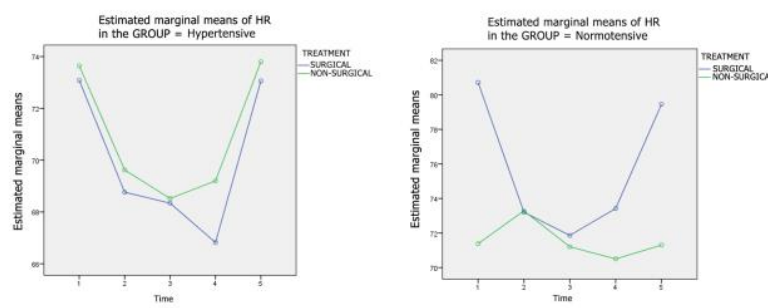

Figure 4. Estimated marginal means of the HR in the hypertensive and normotensive groups (interaction effect between time, group and treatment). Evolution over time through five timepoints.

Evaluation of the effect of time, group and use of vasoconstrictor

In the two study populations, whether or not they were exposed to the use of a vasoconstrictor, the time factor involved a similar evolution of the study variables, without distinguishing between groups of normotensive versus hypertensive participants with antihypertensive treatment. There was a significant progressive increase in SBP when anaesthesia was used, with or without a vasoconstrictor, between the different measurement timepoints up to level 4 of the intervention period $(\mathrm{p}=0.017)$, producing a significant decrease $(\mathrm{p}=0.001)$, until the recovery of the initial levels in the last measurement. From the initial determination until the beginning of the intervention (timepoints 1 and 2), there was a significant decrease in HR $(\mathrm{p}=0.0001)$, producing a significant increase $(p=0.0001)$, until the recovery of the initial levels in the last measurement (Figure 5). No significant differences were observed regarding the DBP variations.

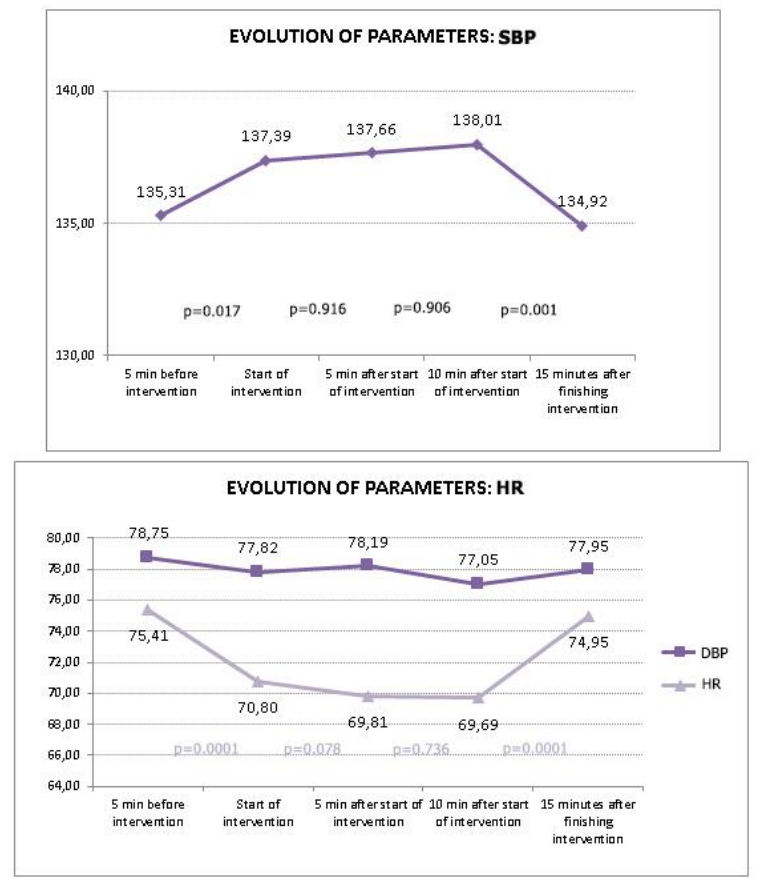

Figure 5. Evolution of SBP and HR. Evolution over time through five timepoints with the use of a vasoconstrictor.

The evolution of some of the study variables was different with the use of anaesthesia with or without a vasoconstrictor, without distinguishing between groups of normotensive versus hypertensive participants with antihypertensive treatment. From 5 minutes before the intervention until the beginning of the dental treatment (timepoints 1 and 2 of measurement), SBP increased sharply in participants without a vasoconstrictor, while in participants exposed to a vasoconstrictor, SBP remained stable; the difference was significant $(p=0.038)$. Initially, DBP decreased significantly when a vasoconstrictor was used $(p=0.001)$, thus ending with a significant increase $(p=0.018)$, while the use of anaesthesia without a vasoconstrictor produced an evolution of the DBP opposite to the previous evolution (Figure 6). Regarding HR, whether or not a vasoconstrictor was used did not produce significant differences in its evolution.
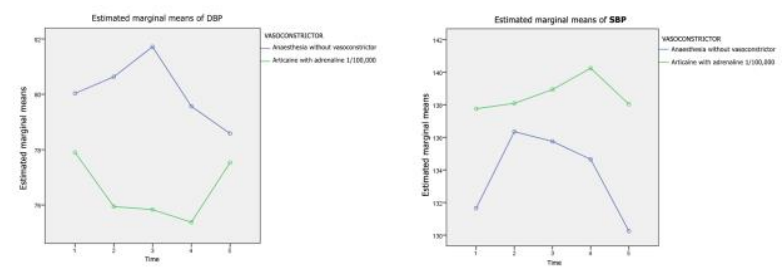

Figure 6. Estimated marginal means of SBP and DBP (interaction effect between time and the use of a vasoconstrictor). Evolution over time through five timepoints. 


\section{DISCUSSION}

Preoperative measurements of BP reduce possible complications that may occur throughout the daily routine of dental practice. ${ }^{5}$ In previous studies ${ }^{1,7,13-}$ ${ }^{25}$, as in the present study, BP values have been recorded during dental treatment. The fact that the BP monitoring is for a limited period of time determines that only punctual information of said values will be obtained. Therefore, to conclusively determine the presence of $\mathrm{WCH}$, ambulatory $\mathrm{BP}$ monitoring should be carried out for 24 hours to exclude WCH and attain a reliable diagnosis. ${ }^{26}$ In our study, the classification of participants according to whether they were normotensive or hypertensive with antihypertensive treatment was based on the medical history provided by the participant; therefore, a possible non-compliance bias cannot be excluded regarding the taking of treatments by a portion of the study population. Five measurement timepoints were established, similar to the more exhaustive studies $7,13,17,20,23$ but unlike other studies that used fewer BP records for monitoring. ${ }^{1}$ 14-16, 18, 19, 21, 22, $24 \mathrm{HR}$ monitoring was determined using a digital sphygmomanometer and Holter monitor, as recommended by some authors in the case of high-risk patients with advanced age ${ }^{12}$, achieving continuous monitoring and avoiding the loss of $\mathrm{BP}$ values.

Regarding the administration of local anaesthesia, negative aspiration was verified because there may be important variations in the haemodynamic changes if a solution of local anaesthetic is accidentally injected into a blood vessel. ${ }^{21,22}$ Local anaesthesia was placed at the time corresponding to the start of the intervention (1st measurement) to determine BP fluctuations. A maximum of three carpules were administered in the group of normotensive participants, according to authors such as Santos et al. ${ }^{27}$ who determined that small amounts of epinephrine appear to show relatively transient cardiovascular effects in healthy subjects. In the group of hypertensive participants with antihypertensive treatment, a maximum of two carpules was established because authors such as Holm et al. and Aubertin et al. ${ }^{28,29}$ established that in patients with cardiovascular disease or uncontrolled hypertension, the maximum number of carpules that can be administered with an epinephrine concentration of $1: 100,000$ is a total of two to four carpules. Patients with hypertension are considered a high-risk group when they are administered local anaesthesia with a vasoconstrictor because epinephrine shows a high potential to increase BP levels and thus leads to the possibility of suffering a cardiovascular event. ${ }^{30,31}$ However, international guidelines determine that it is safe to use local anaesthetics containing epinephrine in stage 1 hypertensive patients. $^{29}$ In 1964, the American Dental Association (ADA) and American Heart Association (AHA) established that local anaesthetic solutions containing normal concentrations of a vasoconstrictor were not contraindicated in cardiovascular patients, although they were patients for whom adequate monitoring and aspiration should be performed.

During BP monitoring in normotensive or hypertensive geriatric participants with antihypertensive treatment, the study variables varied in different ways throughout the interventions, to end up recovering after 15 minutes of concluding the intervention. Thus, at the beginning, the SBP increased progressively and then decreased between the two final measurement timepoints to thus return to the initial values. The DBP decreased between the first and the second periods of evaluation and then increased between the fourth and fifth timepoints. The HR decreased until the third timepoint, where it remained and then recovered at the end. These results are in agreement with the majority of previous studies. ${ }^{7}$ 13, 20, ${ }^{23}$ However, these results differ from a study by Gortzak et al. ${ }^{14}$ probably because they stated that none of the participants were too anxious because they knew that they would only undergo a routine dental check-up; therefore, any fear of treatment involving anaesthesia or invasive treatment could be ruled out. These variations in the increase in the initial measurements could be related to a situation of stress and anxiety. ${ }^{6,18,19,32}$ Surgical treatments may cause higher levels of stress and anxiety in some participants, which may 
relate to increased $\mathrm{BP} .{ }^{33}$ Stress generated by pain, anxiety or distress may cause variations in BP and HR. $^{34-37}$

The use of epinephrine in local anaesthesia increases the depth and duration of the anaesthetic and reduces bleeding and the absorption of the local anaesthetic in the operative field. ${ }^{38,39}$ The use of a vasoconstrictor in the local anaesthetic will allow better pain control than anaesthetics without a vasoconstrictor, avoiding an exaggerated stress response as a result. ${ }^{40}$ In our study, whether or not participants were subjected to surgical treatment, as well as the use of anaesthesia with or without a vasoconstrictor, implied variations in the study variables. The SBP increased between the first and the second timepoints in participants undergoing surgical treatments and with anaesthesia without a vasoconstrictor and decreased between the fourth and fifth timepoints. In participants undergoing non-surgical treatments, the opposite effect occurred: SBP decreased between the first and the second timepoints and then increased between the fourth and fifth timepoints. With the use of a vasoconstrictor, SBP remained stable. The DBP showed no interaction effect in relation to surgical or non-surgical treatments. Only at the beginning did DBP show higher values for the participants with surgical treatments; with the use of a vasoconstrictor, DBP showed an initial decrease, while without a vasoconstrictor, it showed an initial increase. HR was analogous whether or not a vasoconstrictor was used; between the first and the second timepoints, it decreased with surgical and non-surgical treatments and then increased between the fourth and fifth timepoints. BP variations according to the type of treatment and use of anaesthesia with a vasoconstrictor are in agreement with most previous studies ${ }^{18,21,24,41}$, differing only from a study by Abu-Mostafa et $a l .^{22}$ These differences could be attributed to the different amounts of local anaesthetics used. In our study, a maximum of three carpules were used, corresponding to $5.4 \mathrm{ml}$ of local anaesthetic containing $0.054 \mathrm{mg}$ of epinephrine, while in their study, they used $3.6 \mathrm{ml}$ of local anaesthetic containing $0.036 \mathrm{mg}$ of epinephrine. The present results could help explain the discrepancies cited above, agreeing with authors such as KnollKohler et al. ${ }^{42,43}$ who established that pain control was lower in participants who received a local anaesthetic without a vasoconstrictor, compared with participants who were exposed to a local anaesthetic with a vasoconstrictor.

Significant differences were observed in the evolution of SBP, with an initial increase in participants undergoing surgical treatments and without the use of a vasoconstrictor and a decrease with non-surgical treatments; but with the use of a vasoconstrictor, SBP remained stable. The DBP had no interaction effect in surgical or non-surgical treatments; it initially decreased with the use of a vasoconstrictor, while without a vasoconstrictor, it was the opposite. The HR initially decreased in participants undergoing surgical and non-surgical treatments and was analogous whether or not a vasoconstrictor was used.

We propose to carry out studies that differentiate additional population groups, such as an undiagnosed hypertensive population and a diagnosed hypertensive population, treated but not controlled.

\section{CONCLUSIONS}

During blood pressure monitoring, blood pressure variations occur, but there was no clinical repercussion in the participants because once the treatment concluded, a return to the initial values was observed.

\section{ACKNOWLEDGEMENTS}

This study was supported by the International University of Catalonia. Thanks to the participants of this study for their cooperation and contribution to clinical research. The authors declare no potential conflicts of interest with respect to the authorship and / or publication of this article. This research did not receive any specific grants from funding agencies in the public, commercial or notfor-profit sectors.

\section{CONFLICTS OF INTEREST}

None

\section{REFERENCES}

1. Nichols C. Dentistry and hypertension. J Am Dent Assoc. 1997;128:1557-1562. 
2. Longo DL. Harrison's principles of internal medicine. 18th ed. New York: McGraw-Hill; 2012.

3. Pyle MA, Sawyer DR, Jasinevicius TR, Ballard R. Blood pressure measurement by community dentists. Spec Care Dentist. 1999;19:230-234.

4. Muzyka BC, Glick M. The hypertensive dental patient. J Am Dent Assoc. 1997;128:1109-1120.

5. Lambrecht JT, Filippi A, Arrigoni J. Cardiovascular monitoring and its consequences in oral surgery. Ann Maxillofac Surg. 2011;1:102-106.

6. Bavitz JB. Dental management of patients with hypertension. Dent Clin North Am. 2006;50:547-562.

7. Tsuchihashi T, Takata Y, Kurokawa H, et al. Blood pressure response during dental surgery. Hypertens Res. 1996;19:189-194.

8. Young SL, Karp NV, Karp WB. Dentists' and physicians' attitudes on the role of the dental health care team in a cardiovascular risk factor reduction program. J Public Health Dent. 1990;50:38-41.

9. Palatini P, Palomba D, Bertolo O, et al. The whitecoat effect is unrelated to the difference between clinic and daytime blood pressure and is associated with greater reactivity to public speaking. J Hypertens. 2003;21:545-553.

10. O'Brien E, Asmar R, Beilin L, et al. European Society of Hypertension recommendations for conventional, ambulatory and home blood pressure measurement. J Hypertens. 2003;21:821-848.

11. Altunkan S, Iliman N, Altunkan E. Validation of the Omron M6 (HEM-7001-E) upper arm blood pressure measuring device according to the International Protocol in elderly patients. Blood Press Monit. 2008;13:117-122.

12. Lu P, Gong Y, Chen Y, Cai W, Sheng J. Safety analysis of tooth extraction in elderly patients with cardiovascular diseases. Med Sci Monit. 2014;20:782788.

13. Meiller TF, Overholser CD, Kutcher MJ, Bennett R. Blood pressure fluctuations in hypertensive patients during oral surgery. J Oral Maxillofac Surg. 1983;41:715-718.

14. Gortzak RA, Abraham-Inpijn L, Oosting J. Blood pressure response to dental checkup: a continuous, noninvasive registration. Gen Dent. 1991;39:339-342.

15. Agani ZB, Benedetti A, Krasniqi VH, et al. Cortisol level and hemodynamic changes during tooth extraction at hypertensive and normotensive patients. Med Arch. 2015;69:117-122.

16. Abraham-Inpijn L, Borgmeijer-Hoelen A, Gortzak RA. Changes in blood pressure, heart rate, and electrocardiogram during dental treatment with use of local anesthesia. J Am Dent Assoc. 1988;116:531-536.

17. Uzeda MJ, Moura B, Louro RS, da Silva LE, Calasans-Maia MD. A randomized controlled clinical trial to evaluate blood pressure changes in patients undergoing extraction under local anesthesia with vasopressor use. J Craniofac Surg. 2014;25:1108-1110.
18. Silvestre FJ, Salvador-Martinez I, Bautista D, Silvestre-Rangil J. Clinical study of hemodynamic changes during extraction in controlled hypertensive patients. Med Oral Patol Oral Cir Bucal. 2011;16:354358.

19. Chaudhry S, Iqbal HA, Izhar F, et al. Effect on blood pressure and pulse rate after administration of an epinephrine containing dental local anaesthetic in hypertensive patients. J Pak Med Assoc. 2011;61:10881091.

20. Kiyomitsu Y, Sugiyama K, Hirota Y, et al. Blood pressure and heart rate of patients in dental clinics. Anesth Prog. 1989;36:237-238.

21. Abu-Mostafa N, Aldawssary A, Assari A, Alnujaidy S, Almutlaq A. A prospective randomized clinical trial compared the effect of various types of local anesthetics cartridges on hypertensive patients during dental extraction. J Clin Exp Dent. 2015;7:8488.

22. Abu-Mostafa N, Al-Showaikhat F, Al-Shubbar F, Al-Zawad K, Al-Zawad F. Hemodynamic changes following injection of local anesthetics with different concentrations of epinephrine during simple tooth extraction: A prospective randomized clinical trial. J Clin Exp Dent. 2015;7:471-476.

23. Ogunlewe MO, James O, Ajuluchukwu JN, Ladeinde AL, Adeyemo WL, Gbotolorun OM. Evaluation of haemodynamic changes in hypertensive patients during tooth extraction under local anaesthesia. West Indian Med J. 2011;60:91-95.

24. Hashemi SH, Ladez SR, Moghadam SA. Comparative Assessment of the Effects of Three Local Anesthetics: Lidocaine, Prilocaine, and Mepivacaine on Blood Pressure Changes in Patients with Controlled Hypertension. Glob J Health Sci. 2016;8:54157.

25. Bader JD, Bonito AJ, Shugars DA. A systematic review of cardiovascular effects of epinephrine on hypertensive dental patients. Oral Surg Oral Med Oral Pathol Oral Radiol Endod. 2002;93:647-653.

26. Trenkwalder P. Automated blood pressure measurement (ABPM) in the elderly. Z Kardiol. 1996;85:85-91.

27. Santos CF, Modena KC, Giglio FP, et al. Epinephrine concentration $(1: 100,000$ or $1: 200,000)$ does not affect the clinical efficacy of $4 \%$ articaine for lower third molar removal: a double-blind, randomized, crossover study. J Oral Maxillofac Surg. 2007;65:2445-2452.

28. Holm SW, Cunningham LL, Jr., Bensadoun E, Madsen MJ. Hypertension: classification, pathophysiology, and management during outpatient sedation and local anesthesia. J Oral Maxillofac Surg. 2006;64:111-121.

29. Aubertin MA. The hypertensive patient in dental practice: updated recommendations for classification, prevention, monitoring, and dental management. Gen Dent. 2004;52:544-552. 
30. Gungormus M, Buyukkurt MC. The evaluation of the changes in blood pressure and pulse rate of hypertensive patients during tooth extraction. Acta Med Austriaca. 2003;30:127-129.

31. Perusse R, Goulet JP, Turcotte JY. Contraindications to vasoconstrictors in dentistry: Part II. Hyperthyroidism, diabetes, sulfite sensitivity, cortico-dependent asthma, and pheochromocytoma. Oral Surg Oral Med Oral Pathol. 1992;74:687-691.

32. Brand HS, Gortzak RA, Abraham-Inpijn L. Anxiety and heart rate correlation prior to dental checkup. Int Dent J. 1995;45:347-351.

33. Wada M, Miwa S, Mameno T, Suganami T, Ikebe K, Maeda Y. A prospective study of the relationship between patient character and blood pressure in dental implant surgery. Int J Implant Dent. 2016;2:21.

34. Chobanian AV, Bakris GL, Black HR, et al. Seventh report of the Joint National Committee on Prevention, Detection, Evaluation, and Treatment of High Blood Pressure. Hypertension. 2003;42:12061252 .

35. Winter KH, Tuttle LA, Viera AJ. Hypertension. Prim Care. 2013;40:179-194.

36. Arnett DK, Claas SA. Preventing and controlling hypertension in the era of genomic innovation and environmental transformation. JAMA. 2012;308:17451746.

37. Pilgrim JA. Psychological aspects of high and low blood pressure. Psychol Med. 1994;24:9-14.

38. Bader JD, Bonito AJ, Shugars DA. Cardiovascular effects of epinephrine in hypertensive dental patients. Evid Rep Technol Assess (Summ). 2002;48:1-3.

39. Jastak JT, Yagiela JA. Vasoconstrictors and local anesthesia: a review and rationale for use. J Am Dent Assoc. 1983;107:623-630.

40. Malamed SF. Handbook of local anesthesia. 5th ed. St. Louis, Mo.: Elsevier/Mosby; 2004. xiii, 399 p. p.

41. Nakamura Y, Matsumura K, Miura K, Kurokawa H, Abe I, Takata Y. Cardiovascular and sympathetic responses to dental surgery with local anesthesia. Hypertens Res. 2001;24:209-214.

42. Knoll-Kohler E, Fortsch G. Pulpal anesthesia dependent on epinephrine dose in $2 \%$ lidocaine. A randomized controlled double-blind crossover study. Oral Surg Oral Med Oral Pathol. 1992;73:537-540.

43. Knoll-Kohler E, Knoller M, Brandt K, Becker J. Cardiohemodynamic and serum catecholamine response to surgical removal of impacted mandibular third molars under local anesthesia: a randomized double-blind parallel group and crossover study. J Oral Maxillofac Surg. 1991;49:957-962. 